\title{
The Research of the Chinese-English Cultural Difference and Its Influence on English Culture Teaching in Colleges \&Universities
}

\author{
Cao Xueping \\ Foreign Language Research Center, Shaanxi Academy of Governance, Shaanxi, China, 710068
}

Keywords: Cultural Difference; High Colleges and Universities; English; Cultural Teaching

Abstract: With the development of society and the progress of the times, especially in the tide of economic globalization, it's not possible for any country to exist and develop solely. So is the communication among countries. The development of education also cannot be done and should be continuously improved in the communications. English, as an international exchange language, has been playing a pivotal role in foreign exchange. The research of Chinese-English cultural difference is the foundation to do the task of English cultural teaching well.

As nowadays society is rapidly developing, the irresistible tendency of globalization has been affecting the corners of our lives. In the process of globalization, English, as an international exchange tool, has an irreplaceable status. Most countries have set up English courses. Although the English courses in China are set late, over the recent years of development, they have presented a complete educational teaching system. We often divide the world into simply the Chinese and Western countries, and those English-speaking countries are typical Western countries. Since the reform and opening up started, we have had a deeper understanding of the Western world, but from a cultural point of view, our understanding of the Western is still at a superficial level. You may know the Eiffel Tower in France and know the British Parliament. But if let you list some cultural difference of the Western countries from ours, I believe that many people can only speak a few words. On the one hand, this is due to the fact that the massive has experienced a few foreign life; on the other hand, the solution to have a knowledge of the culture can not be done overnight, but a long-term process.

Since the setting of our higher English educational teaching system, we have achieved remarkable achievements in many aspects, but from some perspective, this system is not complete. The research of cultural differences between China and the West is the weakest section of the entire higher English teaching system. This has both historical reasons and reasons for our system itself. What is more is the result of ideas of our school-launching and school-running concepts. 


\section{The Significance of the Research of the Chinese-English Cultural Difference on the Teaching of English Culture in Colleges and Universities}

To understand the significance of the research of Chinese-English cultural differences in the teaching of English culture in colleges and universities, we should understand the relationship between culture and language. Every language is the reflection of culture. It is unrestrained to say that the language that leaves the culture belongs does not exist. All language forms are inevitably labeled with cultural symbols and national color. Since differences of the cultural background exist, their understanding and cognition of the same thing may have completely different results when those people speaking different languages talk. This is why we can laugh in face of the same problem, but some Westerners are serious and even angry. Language is an inseparable part of culture, and language plays a very important role in the inheritance and spread of culture. Some sociologists even think language as the base of culture, and if no language there is no culture. In learning a foreign language, if simply thinking that grammar and words are composed of all the learning, such learners are not able to truly master the language. When we learn language, the first prerequisite is to seriously study how people who speak this language view things, how to observe the world, how to express themselves. We should to seriously learn the thoughts, habits and behaviors of those who speak this language.

In the nowadays of economic society development, language has become a carrier of culture and the reflection of culture in social communications. The anthropologist Malinowski once bluntly pointed out that language is rooted in the nation that speaks the language, rooted in the culture and customs of the nation. If you don't understand this, it is difficult for you to truly understand the language of the nation. .

The Chinese-English cultures have huge differences. Therefore, understanding the similarities and differences of two cultures plays a decisive role in the teaching of English culture in colleges and universities and even the whole English teaching.

\section{Comparison of Chinese-English Differences}

The Chinese-English cultural differences are mainly summarized as aspects below:

\subsection{Similarities and Differences of Time Concept}

The understanding of time by Chinese and the Western embodies the cultural differences. The Chinese people's understanding of time basically stays state that an inch of time is an inch of gold, and it is impossible to buy an inch of time with an inch of gold. The punctuality is the most basic respect for time as if fleeting. The one-inch gold here is not to equate time with money, but to express preciousness of time. Westerners' time concepts are associated with money concepts, and time often represents money. We can see that many times, the Western compensation standard is really based on time, but this is incomprehensible in the oriental cultural atmosphere.

\subsection{Differences of Privacy}

Chinese people prefer to the thrilling sight, we can often see a crowd of people are gathering together unscrupulously, talking interestingly with ease. Compared with the Western, privacy concept of Chinese people is relatively weak. They have no strong concept of individuals. They resume that individuals are always a part of the collective. The existence of individuals is only to foil the collective. All unite friendly and help with each other. Therefore, the Chinese are very willing to hear the ups and downs of others, and they are willing to tell their privacy to each other. 
However, the Western pay special attention to the protection of privacy. They are more concerned about private space and do not allow others to interfere with their own lives. For example, Westerners are more afraid of others inquiring their age and marital status, income, and even occupation. But in the eyes of the Chinese, these issues are very normal. However, if their friends do not know about these issues, there is no difference from strangers.

\subsection{Differences in the Greetings of Polite Formulas}

For the polite formulas greetings, both Westerners and Chinese are able to talk. As influenced by Confucian culture, Chinese people are more modest overall, often setting off other stalwart with their humbleness. In the interpersonal communication, they emphasize the humble ego and respect for others. They regard this as a virtue. Therefore, even if the Chinese make the earth-shattering achievements, they are very restrained in their expression method, and often attribute their merits to others or to the best of time. When praised by others, the Chinese first ly depreciate themselves. But westerners are totally different. When they are praised by others, they tend to accept it happily. Some Chinese think that Westerners are too arrogant and blindly confident. In fact, this is a misunderstanding. Their acceptance of praise is not self-pride, but culture drives behind. They do not think that the self-depreciation will have any substantial impact on the whole incident. Yet even think that this is a dishonest performance.

\subsection{Differences of Dietary Culture}

Both the Eastern and the Western have a tradition of hospitality. In social occasions, Chinese people often exchange each other for a cigarette and toast each other. The host usually orders a table full of wine and meals. They think that no matter how much the guests can enjoy, their politeness should be presented. When the guests express their gratitude, the host habitually express apology and thinks that he has not done well enough. During the banquet, the host is used to using his chopsticks to pick up the dishes in the guests' bowls or on the plates. He also advises the guests to enjoy more, drink more, and eating enough is the minimum standard of hospitality. However, Westerners are very unaccustomed to this. Based on mutual respect for privacy, they often have enthusiasm and leave sufficient space for each other, so that neither the host and the guest will have the feeling of forcing others.

\section{The Improvement of English Culture Teaching in Colleges and Universities under the Research of Chinese-English Cultural Difference}

For a long time, China's higher English teaching has been focusing on the language itself, but it has not paid enough attention to the cultivation of students' actual communicative competence socio-cultural feature of language. Even the English cultural teaching of high colleges and universities at present has some satisfactory aspects. Our basic purpose of the research of the Chinese -English cultural difference is to take the results of the research as an entry point to effectively improve the overall quality of English cultural teaching in China, and then to improve the overall English teaching level of Chinese colleges and universities. At present, this issue has got attention from many educators. Whether in the theoretical research or in the teaching practice, efforts have been made and bold explorations in which great achievements have been made. I believe that to do a good job in teaching English culture in colleges and universities, we should mainly do the following work: 


\subsection{Improve the cultural quality of teachers}

The main reason why I pace this question at the first place is that the overall quality of English language teaching teachers from colleges and universities in China is not high. This has much to do with China's nation conditions and educational teaching system. Due to the limitations of the conditions before, English teachers in colleges and universities rarely have the opportunity to go abroad. Their understanding of English culture is mainly through pictures. This contact itself is dull and superficial. It is difficult to really feel the actual English cultural atmosphere. Moreover, the sentiments obtained in this way are basically biased and isolated. As the connection between many cultural factors is separated, it is difficult to form a complete cognitive system. Furthermore, the English language teachers in China are basically graduated with English major. Their understanding of Chinese- English cultural differences is obtained by self-learning or through secondary training. Courses for professional culture differences are rarely set in normal colleges. These factors have led to the comprehensive quality of English culture teachers in colleges and universities in China to be low, and many teachers have even been temporarily assigned by the colleges or universities. Therefore, in order to achieve a qualitatively leaping improvement of the college English culture teaching, we must work hard to improve the cultural quality of teachers and enhance the comprehensive ability of teachers.

\subsection{Integrate cultural teaching into the entire English teaching system}

The English course system all over colleges and universities in China is not the same. Some set up cultural courses separately, and some things are arranged throughout a certain course. However, due to the influence of the teaching progress and the arrangement of the course, the class hours related to cultural differences are very limited. Due to the limitations of the conditions, some colleges have even shortened the class-hour of the cultural courses to ensure the education and teaching in grammar and vocabulary. Textbooks of some colleges are unreasonable, which do not scientifically and rationally arrange the cultural teaching into the textbooks. Many teaching materials also need seeking by teachers provisionally. It is a systematic project to integrate cultural teaching into the entire English teaching system that requires the joint efforts of the colleges and teachers to fulfill. What gratifies us in recent years is that many colleges have noticed the importance of cultural teaching and have taken various measures to ensure the smooth implementation of cultural teaching within their ability. In the process of implementing cultural teaching, teachers should fully cultivate the enthusiasm and initiative of students to participate, have students take part in courses, can not separate teaching from learning, try to find content that students are interested in, and try to adopt the way that students are interested to express. Only in this way can the development of teaching and learning form a benign improvement.

\subsection{Focus on the improvement of teaching methods}

With the development of the times and the advancement of science and technology, the high-tech system with the Internet and new media as present is getting more and more, and stepping into our lives deeper and deeper. The Internet and new media represent the future development trend, and the development of all walks of life is irreplaceable to link to the two.

Currently, the huge trend of global educational reforming is to focus on the personality of the individual to be educated, to carry out personalized education that are proper for individual features, and to emphasize the personality development of students. This has something in common with the quality education advocated in China now. At present, what to apply widely is multimedia. These are just the most basic applications of education and teaching under the conditions of 
Informatization and Internet. As far as multimedia course is concerned, only a simple application point though it is, it greatly increases the classroom capacity of teachers, in which teachers can present rigid teaching content to students in a way combined with sound and image. The traditional education and teaching are complementary each other to that based on the Internet and new media. The traditional teaching mode takes the teacher as the core and support point of education and teaching. The teacher lectures and the students listen. The education and teaching under the conditions of the Internet and new media can separate teachers' lecturing from the students' listening in terms of form. The students' learning and the teacher's teaching are no longer limited by the time and place, and the form of education and teaching has been greatly expanded. In terms of college English culture teaching, the convenience makes students to use the campus network and mobile phones to read anytime, anywhere. Meanwhile, the content of reading is no longer rigid, but colorful and interesting which greatly enhance students' interest in learning and stimulate their desire to read.

\section{Conclusion}

As Chinese-English cultural exchanges increasingly enhance and deepen, that people have an understanding of the similarities and differences between Chinese and English cultural is also becoming more and more profound. As the main front for cultivating talents for social construction in the new era, colleges and universities should take the social demand as the lead, the discipline construction as the link, do the research work in the early stage of Chinese- English cultural difference and apply achievements to the actual teaching, so that work hard to cultivate a high-quality professional talent team for the society more and better.

\section{References}

[1] Zhang Jingbo. Translation of English and American Literature in College English Teaching under the Chinese and Western Cultural Differences [J].Campus English,2014(35)238-239.

[2] Song Haifeng. The Influence of Exploring Chinese and Western cultural differences on Business English Translation and its Countermeasures [J]. Overseas English, 2015 (3) 127-128.

[3] Qu Renxiong. Higher Vocational English Teaching should strengthen the Education of Chinese and Western Cultural Differences [J]. Chinese Off-campus Education, 2014 (4) 137-139.

[4] Hou Guanxiang, Shi Lixiong. The Discussion on the Sources of Chinese and the Western Cultural Differences [J]. Culture and Education Materials, 2015 (22) 67-68.

[5] Gu Jiaxi. The Discussion on the Influence of Chinese and Western Cultural Differences on Intercultural Communication [J].Northern Literature, 2017(9)145-146.

[6] Yin Pingyao, Liu Jingxia. The Influence of Chinese and Western Cultural Differences on English Learning [J]. Overseas English, 2018(2)115-117.

[7] Lu Na. Exploring the Influence of Chinese and Western Cultural Differences on Intercultural Communication Activities [J]. Theoretical Observations, 2017 (10) 162-164.

[8] Yang Yanting. The Analysis of Modern Chinese and Western Cultural Differences and English Teaching [J]. Tomorrow's Fashion, 2018(7)95-97. 